\title{
Surface Treatment Technology for Increasing Wear Resistance of Aluminum Alloy
}

\author{
Fan Lidan ${ }^{1, a^{*}}$, Chen Youquan ${ }^{2, b}$, Yang Feng ${ }^{1, c}$, Yang Zhuojuan ${ }^{1, d}$
}

1College of Mechanical Engineering Jilin Teachers' Institute of Engineering \& Technology Changchun, China

${ }^{2}$ Department of Mechanical Engineering Changchun Institute of Engineering Technology Changchun, China

${ }^{a}$ Fanlidan111@163.com, ${ }^{b} Q u a n 3168 @$ sina.com, yangfeng@163.com*

Keywords: Engine; Aluminum alloy parts; Plasma; Laser

\begin{abstract}
Research and application of various surface treatment technologies in increasing the wear performance of aluminum alloy engine parts are introduced. These technologies include plasma spraying, plasma arc welding, plasma scanning, plasma electrolyzing, electroplating,physical vapour deposition and laser cladding technologies. Vistas of application of surfacestrengthening aluminum alloy wear resistant parts are prospected.
\end{abstract}

\section{Introduction}

The lightweight of automobile and motorcycle is a very important development trend. Potential the whole or part of the body material is made of high density steel. Iron material replaced by a small density of aluminum alloy material, you can greatly reduce the car Body mass. Engine mass in the body mass in a large proportion of the engine is replaced by the original cast iron material for aluminum alloy. Poor wear resistance, if not processed, will make the engine cylinder wall. In contact with the piston part of the production of serious wear and tear, greatly reduce the engine service life of.

At present, the general solution is in the aluminum alloy engine with a cast iron cylinder liner, Piston rings and cast iron cylinder liners instead of aluminum alloy gold material for friction, so as to avoid the wear of aluminum alloy. But this method is complicated, and the quality of the aluminum alloy cylinder block is increased at the same time. By surface treatment technology, the surface of aluminum alloy is formed and adhered firmly in the surface layer of metal, alloy and ceramic, the wear resistance of the work piece can be improved, therefore, it is widely valued and studied at home and abroad. To this end, this article nearly some of the results of the study are as follows.

\section{Plasma Spraying}

The invention of 1998 Germany Chrysler company used technology Aluminum Alloy cylinder wall $\mathrm{Al}-\mathrm{Si}$ eutectic alloy and / or Al-Si complex coating of the internal combustion engine. The layered structure is composed of $\mathrm{Al}$ solid solution, $\mathrm{Si}$ deposit, intermetallic phase (for example, $\mathrm{A}_{12} \mathrm{Cu}$ and $\mathrm{Mg}_{2} \mathrm{Si}$ ) and oxide. The coating is formed by thermal spraying, preferably by atmospheric plasma spraying, with high adhesion and wear resistance ${ }^{[1]}$. In 2004, soil ear V., Turkey et al. Used plasma spraying technology to prepare the thickness of about $400 \mathrm{~m}$ (Al-Si) -Sic composite coating on Al-Si alloy piston of diesel engine. The microstructure of coating was studied by means of optical microscopy, SEM and $\mathrm{X}$. It was found that the coating was stratified by the deposition and solidification of continuous melting or semi molten particles. The SiC particles were dispersed randomly in the Al-Si layer. The average micro hardness of the (Al-Si) -Sic was $167 \mathrm{HV}$ (mass fraction).

\section{Plasma arc Welding}

1995 South Korea Institute of machinery and metal invention improve wear resistance technology Aluminum Alloy piston ring groove plasma arc welding surface treatment ${ }^{[2]}$, which comprises the following steps: 1) will be placed in the plasma torch Aluminum Alloy piston top ring groove; 2) to 
provide 50 to $200 \mathrm{mu} \mathrm{m}$ copper; 3) arc welding part of piston; 4) with copper melt metal melting piston, forming $\mathrm{Al}-\mathrm{Cu}$ alloy coating; 5) the top ring groove is formed on the alloy surface. Because the composition of the alloy surface is uniform, the top ring groove has a high wear resistance ${ }^{[3]}$.

\section{Plasma Electrolysis}

In 2001 the College of mechanical and electronic engineering Shandong University of Science and Technology invented a method of coating formed by plasma cladding gradient scanning of metal surface, which comprises the following steps: 1) in the mixed metal powder coated with Fe based or Co based or Ni based or according to the requirement of preparation of alloy powder and ceramic powder at the end; 2) produce ionization in the plasma torch with non oxidizing gas plasma on the metal surface scanning, produce metallurgical bonding of the cladding layer or gradient coating. The effect of A. pre coating by plasma cladding, the formation of non-equilibrium microstructure containing ceramic particles in the metal surface; B. suitable powder type and process parameters of the plasma heating automatic generation of ceramic particles were cladding ${ }^{[4]}$ continuous gradient distribution.

\section{Electroplate}

After 1997, TOYOTA Japan Institute of technology gradually developed high-speed plating, surface preparation for Aluminum Alloy matrix (Ni-P) technology of -SiC gradient composite coating, deposition layer with diameter $6 \sim 30 \mathrm{~nm}$. After the surface layer is deposited on Ni3P, the surface hardness of the aluminum alloy substrate is up to $1035 \mathrm{HV}^{[6]}$. Compared with the traditional method, the coating has a super high bonding strength ${ }^{[7]}$. In 1996, Japan's ASAHI Technology Research Industry Co., Ltd. patent technology for the aluminum alloy cylinder wall coating metal plating solution, in order to improve the binding force of the metal coating ${ }^{[8]}$.

The development of the United States in 1997 GM Hughes electronics company success in Aluminum Alloy piston plating iron cobalt alloy technology and patented ${ }^{[9]}$, which comprises the following steps: 1) by electro less nickel electrolyte in Aluminum Alloy matrix on a nickel plated layer; 2) by iron cobalt electrolyte in the nickel layer electroplating iron cobalt alloy. The aluminum alloy parts obtained by Fe Co coating have good adhesion, friction, thermal conductivity and corrosion resistance.

In 2001 China Taiwan Sanyang industrial Limited by Share Ltd invented the manufacture of aluminum composite electroplating cylinder: first to provide a cylinder embryo mould, then the preparation of aluminum metal liquid, and then the implementation of die casting, the pressure exceeds $20 \mathrm{MPa}$, low speed and high speed is greater than $0.03 \mathrm{~m} / \mathrm{s}$ greater than $1 \mathrm{~m} / \mathrm{s}$ filled aluminum metal liquid enters the cylinder mould to the embryo the formation of a cylinder body; the cylinder body diameter to form electroplating $\mathrm{Ni}-\mathrm{SiC}$ composite coating ${ }^{[10]}$.

Aluminum Alloy engine cylinder wall invented in 1999 Shanghai kingside rim Co. Ltd. (Ni-SiC) composite plating process, plating solution composition is $410 \sim 500 \mathrm{~g} / \mathrm{L}$ nickel sulfate, nickel chloride $5 \sim 9 \mathrm{~g} / \mathrm{L} 41 \mathrm{~g}$ to $60 / \mathrm{L}$, boric acid, silicon carbide $50 \sim 100 \mathrm{~g} / \mathrm{L}$ stress relieving agent $1 \sim 3 \mathrm{G} / \mathrm{L}$ from 0.1 to 0.3 , dispersant $\mathrm{g} / \mathrm{L}$. The technology makes the engine cylinder wear and durability, the discharge of waste gas and the cold start performance increase ${ }^{[11]}$.

\section{Physical Vapor Deposition}

On 1999 General Motors Corporation scratching and friction behavior of various Aluminum Alloy piston group of coating on $390 \mathrm{Al}$ engine cylinder hole, the tested coating including $\mathrm{Ni}-\mathrm{W}$ coating, electro less Ni layer, with $\mathrm{BN}$ or $\mathrm{SiC}$ or $\mathrm{Si} 3 \mathrm{~N} 4$ ceramic particles of Ni-P coating and TiN physical vapor deposition (PVD) coating, diamond (DLC) coatings and the hard anodic oxidation treatment. Ni-P ceramic composite coating is prepared by the traditional electroplating method, (Ni-P) -SiC coating hardness is about $55 \mathrm{HRC}$, (Ni-P) -Si3N4 coating hardness in $50 \sim 55 \mathrm{HRC}$, (Ni-P) -BN coating hardness in $50 \mathrm{HRC}$ or so. The evaluation of these coatings scratch resistance and abrasion resistance 
compared with electro galvanized and galvanized iron. The wear of PVD TiN coating on the $390 \mathrm{Al}$ hole was the most serious ${ }^{[12]}$.

\section{Laser Cladding Forming}

The State Key Laboratory of Huazhong University of Science and Technology 2004 laser experimental research of HBS320 aluminum piston ring groove on both sides of the laser alloy of nickel based alloy powder of $5 \mathrm{KWCO} 2$ laser direct cross flow, obtained the alloying layer free of pores and cracks, the microstructure is fine and uniform. SEM study showed that the alloying layer and the matrix Aluminum Alloy formed a strong metallurgical bonding; the alloying layer near the substrate for Aluminum Alloy has the characteristics of directional solidification dendrite and fine equated grains, uniform transition. The surface hardness is $5 \mathrm{HV}$, which is 650 to 6 times of the base aluminum alloy. The practical application shows that the service life of the aluminum piston is greatly improved by. TiB2 particle reinforced metal matrix composite coating was synthesized by laser cladding on 2024 aluminum alloy substrate by laser cladding in 2006,. The surface micro hardness was up to $900 \mathrm{HV}$. $18 \mathrm{~N}$ load 10min, wear in $2 \sim 3 \mathrm{mg}$.

In recent years, according to the needs of the development of lightweight automobile, the application of aluminum in the car is very fast. 2002 North American car average per vehicle with aluminum has reached $124 \mathrm{~kg}$, Japan in 2005 for each vehicle with aluminum is estimated to reach $150 \mathrm{~kg}$. The parts of the engine, the 1995 BMW 4 valve 6 cylinder engine Otto $(2,2.5,2.8 \mathrm{~L})$, which is 31 light aluminum cylinder block cast cylinder kg; development of the Japanese car company's aluminum engine generally uses the aluminum cylinder, a cast cylinder is reduced by $20 \sim 30 \mathrm{~kg}$.

\section{Friction and Wear Test}

The base material of the test specimen is aluminum alloy, after quenching and tempering treatment, the large size of $45 \#$ steel plate is cut into the required size of the experiment, that is, $20 \mathrm{~mm} * 10 \mathrm{~mm} * 8 \mathrm{~mm}$. From the test plan Table 4-2, we can know that the test process, there are 28 kinds of test specimens, the 84 test, in order to reduce the impact of the test error, each test number were done 3 times. Test steps are as follows:

In order to keep the specimen surface clean, in order to reduce the experimental error, with ethanol before the test in medical ultrasonic cleaner cleaning in 20 minutes, and then in the water for 10 minutes with ultrasonic cleaning, hair dryer, in an electronic balance weighing down as before - wear weight;

It is fixed on the sample table of the micro tribology experiment machine. The GCr15 steel ball with a diameter of 63 and HRC 4, as the grinding element, was chosen as the grinding element. On the test piece to apply $10 \mathrm{KG}$ force on the grinding, each time along the friction surface to walk 3 times, about 90 minutes;

Anhydrous ethanol in medical ultrasonic cleaner cleaning in 20 minutes, and then in the water for 10 minutes with ultrasonic cleaning, hair dryer, weighing as - wear weight in electronic balance;

Samples in the direction perpendicular to the moving direction of the laser longitudinally, embedded and made of grinding and polishing of metallographic samples with $4 \%$ nitric acid alcohol solution corrosion, using Japanese JSM-5310 scanning electron microscope (Scanning Electron microscope observation samples, the test voltage is $25 \mathrm{kV}$, the magnification is 5000 times $50 \sim$. Wear mechanism analysis.

The lost weight of the flat surface of the machine is not processed, and the lost weight of the laser bionic coupling sample and the mechanical processing sample are lost to the curve, as shown in Fig. 1. 


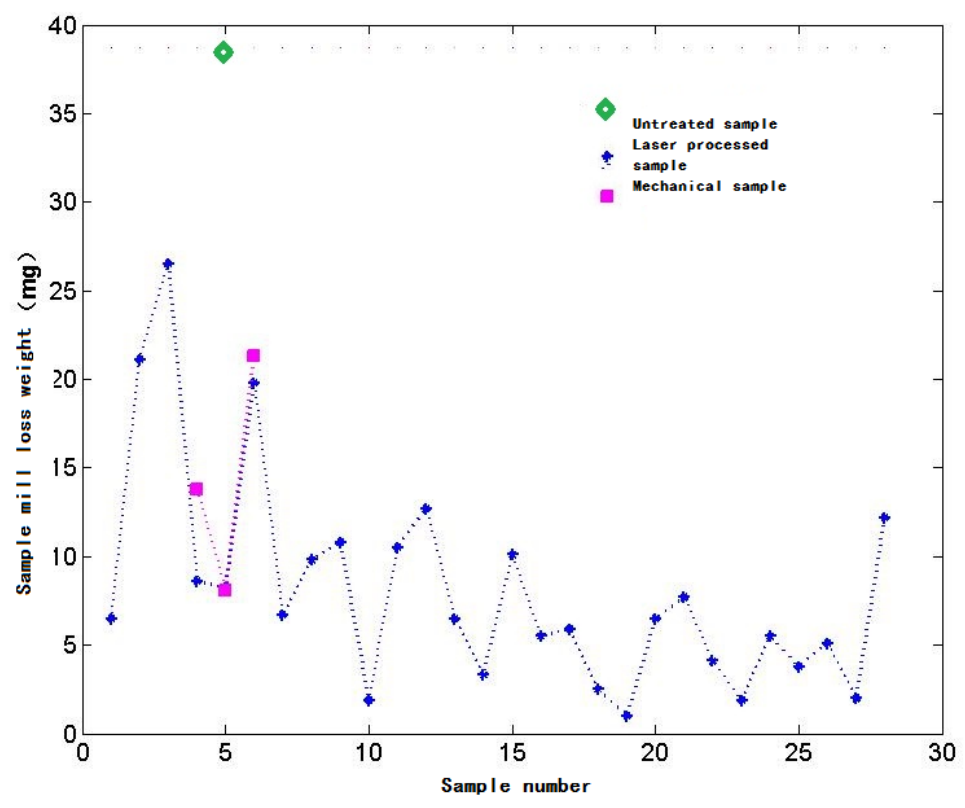

Figure 1. The loss weight contrast curve of sample after wear

\section{Conclusion}

The smooth, Laser Biomimetic Coupling and machining of wear test, found that wear resistance of specimens with optimal laser bionic coupling surface, followed by machining the bionic sample, unprocessed smooth surface wear resistance of the sample is the worst.

Under the same conditions (the same size, distribution interval), the wear resistance of the grid bionic coupling surface sample is the best, the second is the fringe pattern, and the last is the pit type.

In a certain range, the wear resistance increases with the increase of unit size, the more uniform the surface topography is, the better the wear resistance is.

\section{References}

[1] Daimler Chrysler AG. Coating of cylinder walls ofinternal-combustion engine with aluminum-silicon alloys or aluminum/silicon composites [P]. US Pat: US6080360, 2000-06-27.

[2] Turkel V, Celik E, Tekmen C, et al. SiC-AlSi composite coatings on piston alloys for diesel engine

[3] Motors [J]. Journal of Composite Materials, 2004, 38(16): 1449-1456.

[4] Korea Inst Machinery, Metals. Method for improvement the abrasion resistance of aluminum

[5] Piston ring grooves by plasma arc weld surfacing [P]. KR Pat: KR138932, 1995-02-06.

[6] Takeuchi H, Tamura S. Application of electrolyte jet to rapid composite electroplating [J]. SurfaceEngineering, 2004, 20(1): 25-30.

[7] Takeuchi, Hiromitsu. Pretreatment for electroplatingon aluminum alloy substrates by electrolyte jet containing SiC particles [J]. Toyoda Gosei Giho, 1997, 39(2): 79-85.

[8] Sankyo Tokin Kogyo Y K. Bottomed aluminum (alloy) cylinder having metal electroplating oninner wall surface [P]. JP Pat: JP09324299, 1996-06-03.

[9] Hughes Electronics Corp. Electroplating of iron-cobalt alloy onto aluminum alloy parts [P]. US Pat: US5810992, 1997-02-28. 